Tropical Journal of Pharmaceutical Research April 2020; 19 (4): 805-809

ISSN: $1596-5996$ (print); 1596-9827 (electronic)

(C) Pharmacotherapy Group, Faculty of Pharmacy, University of Benin, Benin City, 300001 Nigeria.

Available online at http://www.tjpr.org

Original Research Article

http://dx.doi.org/10.4314/tjpr.v19i4.18

\title{
Metformin exerts renoprotective effect by reducing proteinuria in spontaneously-hypertensive rats
}

\author{
Yuanyuan Liu*, Chengjian Wang, Enyuan Zhang \\ Department of Cardiology, Tianjin Chest Hospital, Tianjin, PR China \\ *For correspondence: Email: uikb2c@163.com \\ Sent for review: 3 February 2019 \\ Revised accepted: 23 January 2020
}

\begin{abstract}
Purpose: To study the mechanism involved in metformin (DMBG)-induced reduction of albuminuria in spontaneously-hypertensive rats (SHRs).

Methods: The SHRs were divided into DMBG SHR group $(n=30)$ given DMBG $(300 \mathrm{mg} / \mathrm{kg})$ and NC SHR group $(n=10)$ given distilled water $(2 \mathrm{ml} /$ day), while Wistar-Kyoto rats $(W K Y)$ rats were divided into DMBG WKY group $(n=30)$ given DMBG $(300 \mathrm{mg} / \mathrm{kg})$ and NC WKY group $(n=10)$ administered distilled water (2 ml/day). Urinary protein levels were measured and compared. Inflammatory infiltration in renal tissue, and expression of vascular endothelial growth factor (VEGF) were assessed. Abdominal aortic blood was used to measure serum levels of creatinine and blood urea nitrogen (BUN).

Results: Urinary protein was markedly elevated in SHRs, while BUN in SHRs was lowered, relative to $W K Y$ rats $(p<0.05)$. Moreover, inflammatory cell population was lower in DMBG SHRs group than in $W K Y$ rats $(p<0.05)$. Kidney expressions of VEGF in SHR and WKY rats treated with metformin were significantly reduced, relative to those in untreated rats, but VEGF-A in DMBG SHR rats was markedly elevated, relative to NC SHR group, and was also raised in DMBG WKY, when compared with NC WKY rats $(p<0.05)$.

Conclusion: Metformin reduces albuminemia in spontaneously hypertensive rats by up-regulating VEGF expression, thereby exerting renoprotective effect. This finding provides ideas for research and development of other therapeutic approaches.
\end{abstract}

Keywords: Metformin, Spontaneous hypertension, Renoprotective, Albuminuria, Kidney, Vascular endothelial growth factor (VEGF)

\begin{abstract}
This is an Open Access article that uses a fund-ing model which does not charge readers or their institutions for access and distributed under the terms of the Creative Commons Attribution License (http://creativecommons.org/licenses/by/4.0) and the Budapest Open Access Initiative (http://www.budapestopenaccessinitiative.org/read), which permit unrestricted use, distribution, and reproduction in any medium, provided the original work is properly credited.

Tropical Journal of Pharmaceutical Research is indexed by Science Citation Index (SciSearch), Scopus, International Pharmaceutical Abstract, Chemical Abstracts, Embase, Index Copernicus, EBSCO, African Index Medicus, JournalSeek, Journal Citation Reports/Science Edition, Directory of Open Access Journals (DOAJ), African Journal Online, Bioline International, Open-J-Gate and Pharmacy Abstracts
\end{abstract}

\section{INTRODUCTION}

Hypertension refers to a clinical syndrome in which systemic arterial blood pressure is increased with or without functional or organic damage to the heart, brain, kidney or any other organ [1]. Arising from the development of the Chinese economy and improvement in living standard, the incidence of hypertension is on the increase. Hypertension often damages many organs, among which the kidney occupies a prominent position [2]. Studies have shown that the probability of renal injury in patients with hypertension is higher than that in normal people, and the incidence of chronic renal insufficiency increases year by year [3]. The 
early clinical symptoms of hypertension are few, and the disease is of slow onset, thereby making it difficult for the affected persons to detect it early. However, when hypertension-associated renal injury symptom such as albuminuria appears, the quality of life of the patient is adversely affected [4]. Therefore, timely control of hypertension and inhibition of renal injury in hypertensive patients have always been the focus of medical research on hypertension worldwide. Metformin (DMBG) is a biguanide drug which inhibits glucose transport, increases insulin sensitivity, reduces blood glucose, and minimizes diabetic complications by reducing blood lipids and increasing promyelocytic activity [5]. It has been reported that metformin reduced urinary protein level in patients with severe hypertension, but the related mechanism is not yet known [6]. This investigation was carried out to unravel the effect of (DMBG) on proteinuria in spontaneously hypertensive rats, and the mechanism involved.

\section{EXPERIMENTAL}

\section{Animals}

A total of 40 SHRs and 40 WKY rats aged $6.5-$ 7.0 weeks, with mean body weight of $122.24 \pm$ $20.42 \mathrm{~g}$, were bought from Beijing tong Lihua Experimental Co. Ltd (biological license: experimental animals SCXK20120001).

This research was approved by the Animal Ethical Committee of Tianjin Chest Hospital, Taierzhuang South Road, Jinnan District, Tianjin City, China (approval no. 201935578), and was carried out in line with the "Principles of Laboratory Animal Care" (NIH, 1985) [7].

\section{Treatment}

The rats were kept at room temperature of 22 $25{ }^{\circ} \mathrm{C}$, relative humidity of $40-60 \%$, and noise level of $\leq 45 \mathrm{~dB}$, in an environment with 12-h round-the-clock natural light, and fed with standard feed and distilled water. The SHR rats were divided into DMBG SHR group $(n=30,300$ $\mathrm{mg} / \mathrm{kg}$ ) and NC SHR group $(\mathrm{n}=10)$, while the WKY rats were assigned to DMBG WKY group $(n=30)$ and NC WKY group $(n=10)$. The NC SHR group and NC WKY group were given drinking water for 5 months.

\section{Evaluation of treatment indicators}

\section{Blood glucose}

Following a 12-h fast, blood was taken from the tail artery of each rat and subjected to centrifugation at $3000 \mathrm{rpm}$ for $15 \mathrm{~min}$. The serum was kept in a refrigerator at $-80{ }^{\circ} \mathrm{C}$ to avoid repeated freezing and thawing, and blood glucose was measured using automatic analyzer.

\section{Systolic blood pressure}

The rats were placed in a quiet environment, and their blood pressure was determined using tail cuff technique. Mean systolic blood pressure (SBP) was obtained three times within $10 \mathrm{~min}$.

\section{Urinary protein}

The urine of the rats was collected for $24 \mathrm{~h}$, and the total urine volume was recorded. The urine was spun at $3000 \mathrm{rpm}$ for $15 \mathrm{~min}$, and its protein content was determined using an Automatic analyzer.

The animals were anesthetized, and $5 \mathrm{~mL}$ of abdominal aortic blood was taken from each rat. The blood was centrifugated at $3000 \mathrm{~g}$ at room temperature for $15 \mathrm{~min}$. Serum creatinine (Cre) and BUN levels of the rats were determined using Automatic analyzer. Tissue was taken from the upper pole of the left kidney, and processed for light microscopy. Paraffinized sections of the kidney tissues were subjected to $H$ \& $E$ staining and examined under the microscope for presence of inflammatory infiltration. The expression of VEGF in the kidney was assayed using immunohistochemistry. The excised rat kidney tissue was made into a homogenate which was stored in polypropylene tube, and the VEGF-A protein concentration was determined with enzyme-linked immunosorbent assay (ELISA).

\section{Statistical analysis}

All measurement data are expressed as mean \pm standard deviation (SD). Inter-group comparison was done using $t$-test. Counting data are expressed as percentage, and $t$-test was used for comparison between groups. Grade data were compared using Ridit test. All statistical analyses were done using SPSS 20.0 software package. Statistical significance was assumed at $p<0.05$.

\section{RESULTS}

\section{Blood glucose, SBP and body weight}

At the end of treatment, there were no significant differences in blood glucose and body weight between SHR rats and WKY rats $(p>0.05)$. The systolic blood pressure of rats treated with 
metformin was significantly different from that of untreated rats $(p<0.05$, Table 1$)$.

\section{Urinary protein, Cre and BUN levels of rats at late stage of treatment}

Rat urine protein content in DMBG SHR group was significantly higher than that of DMBG WKY group, and BUN level of DMBG SHR rats was significantly higher than that of DMBG WKY group. The urine protein and Cre levels in the metformin-treated rats were significantly lower than the corresponding levels in untreated rats $(p$ $<0.05$ ). However, metformin did not exert any marked effect on BUN levels in SHR rats and DMBG rats $(p>0.05)$. These data are shown in Table 2.

\section{Levels of inflammatory cells in rat kidneys at late stage of treatment}

Histological examination showed that NC WKY group and DMBG WKY group had no significant morphological abnormalities in renal tissue, while rats in DMBG SHR group had significantly lower inflammatory cell infiltration than rats in the NC SHR group. Quantitative analysis of $H$ \& $E$ stained sections showed that the level of inflammatory cells in the liver of rats was markedly elevated in SHRs, relative to that in the liver of the WKY group ( $p<0.05)$. Moreover, there were significantly higher number of inflammatory cells in DMBG SHR group than in WKY group ( $p<0.05$; Table 3 and Figure 1).

\section{Renal VEGF expression}

Immunohistochemical studies showed that renal VEGF expressions in SHR rats and WKY rats treated with metformin were downregulated, relative to WKY and SHR rats without metformin treatment.

Table 3: Levels of inflammatory cells in rat kidney at late stage of treatment

\begin{tabular}{|c|c|c|c|}
\hline Group & & $\mathbf{n}$ & $\begin{array}{c}\text { Inflammatory cells } \\
\text { (cells/HPF) }\end{array}$ \\
\hline \multirow{2}{*}{ SHR } & $\begin{array}{l}\text { DMBG } \\
\text { SHR }\end{array}$ & 30 & $153.18 \pm 20.86$ \\
\hline & NC SHR & 10 & $286.16 \pm 26.18 a$ \\
\hline \multirow{2}{*}{ WKY } & $\begin{array}{l}\text { DMBG } \\
\text { WKY }\end{array}$ & 30 & $123.49 \pm 19.48 a b$ \\
\hline & NC WKY & 10 & $134.72 \pm 18.46 a b$ \\
\hline
\end{tabular}

${ }^{a} P<0.05$, vs DMBG SHR group; ${ }^{b} p<0.05$, vs NC SHR group. Values are expressed as mean \pm SD
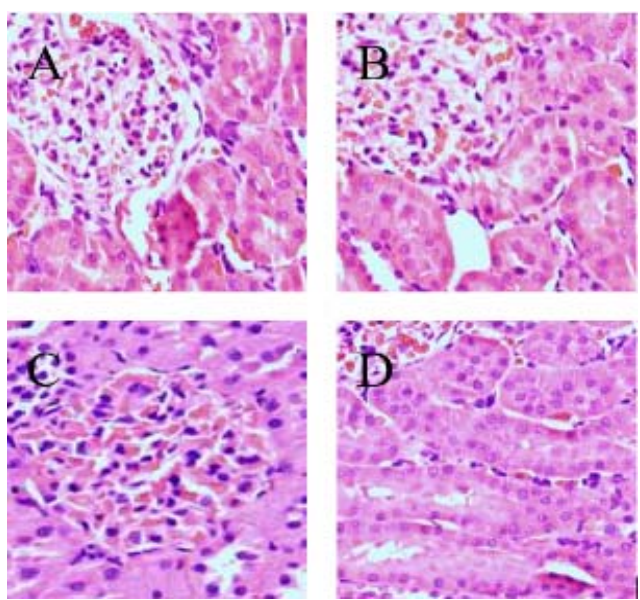

Figure 1: Rat kidney pathology of the various groups. A: renal tissue of rat from NC WKY group; B: kidney tissue of rat from DMBG WKY group; C: renal tissue of rat from NC SHR group; D: kidney tissue of rat from DMBG SHR group (H \& E)

Table 1: Systolic blood pressure, blood glucose and body weight

\begin{tabular}{|c|c|c|c|c|c|}
\hline Group & & $\mathbf{n}$ & SBP $(\mathrm{mmHg})$ & $\begin{array}{l}\text { Blood glucose } \\
\text { (mmol/L) }\end{array}$ & Body weight (g) \\
\hline \multirow[b]{2}{*}{ SHR } & DMBG SHR & 30 & $204.18 \pm 7.14$ & $7.16 \pm 0.15$ & $358.16 \pm 18.16$ \\
\hline & NC SHR & 10 & $208.46 \pm 5.16$ & $7.13 \pm 0.45$ & $363.15 \pm 17.49$ \\
\hline \multirow{2}{*}{ WKY } & DMBG WKY & 30 & $122.42 \pm 5.13$ & $6.93 \pm 0.41$ & $355.18 \pm 18.12$ \\
\hline & NC WKY & 10 & $123.48 \pm 3.46$ & $7.06 \pm 0.23$ & $362.15 \pm 20.44$ \\
\hline
\end{tabular}

Values are expressed as mean \pm SD

Table 2: Urinary protein, Cre and BUN levels at the late stage of treatment

\begin{tabular}{|c|c|c|c|c|c|}
\hline Group & & $\mathbf{n}$ & $\begin{array}{c}\text { Urinary protein } \\
\text { (mg/24h) }\end{array}$ & Cre ( $\mu \mathrm{mol} / \mathrm{L})$ & BUN (mmol/L) \\
\hline \multirow{2}{*}{ SHR } & DMBG SHR & 30 & $28.16 \pm 7.46$ & $40.15 \pm 1.46$ & $10.43 \pm 0.16$ \\
\hline & NC SHR & 10 & $47.76 \pm 10.46 a$ & $51.43 \pm 1.86 a$ & $11.43 \pm 1.26$ \\
\hline \multirow{2}{*}{ WKY } & DMBG WKY & 30 & $16.45 \pm 3.18 a b$ & $41.16 \pm 1.41$ & $8.16 \pm 0.73 a b$ \\
\hline & NC WKY & 10 & $19.73 \pm 3.52 a b c$ & $49.15 \pm 1.67 c$ & $8.49 \pm 0.82 a b$ \\
\hline
\end{tabular}


As shown in Table 4 and Figure 2, ELISA revealed that VEGF-A level in the DMBG SHR group was significantly higher than that in the NC SHR group, and VEGF-A level in the DMBG WKY group was significantly higher than that in the NC WKY group $(p<0.05)$.

Table 4: Renal VEGF expression among the groups at the late stage of treatment

\begin{tabular}{llcc}
\hline Group & & $\mathbf{n}$ & VEGF-A (pg/mg) \\
\hline \multirow{2}{*}{ SHR } & DMBG SHR & 30 & $175.42 \pm 20.15$ \\
& NC SHR & 10 & $69.51 \pm 11.15 \mathrm{a}$ \\
\multirow{2}{*}{ WKY } & DMBG WKY & 30 & $152.58 \pm 14.20$ \\
& NC WKY & 10 & $68.25 \pm 8.15 \mathrm{~b}$ \\
\hline
\end{tabular}

${ }^{\mathrm{a} P}<0.05$, vs DMBR SHR group; ${ }^{\mathrm{b}} p<0.05$, vs NC $\mathrm{SHR}$. Values are expressed as mean $\pm \mathrm{SD}$
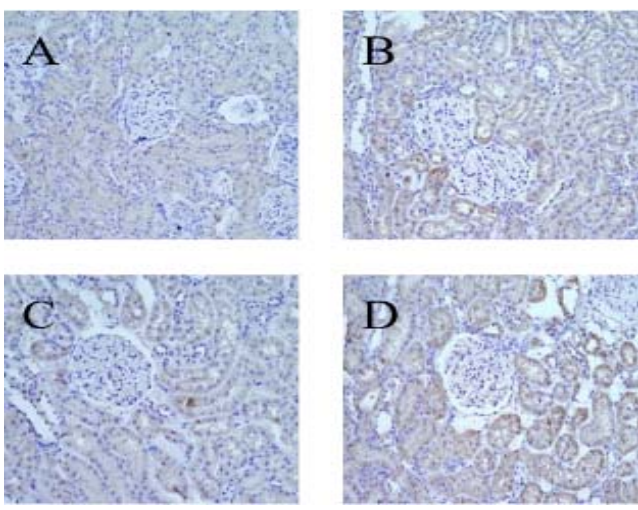

Figure 2: Images of rat kidney immune tissue (brown represents VEGF). A: renal tissue of NC WKY group; B: kidney tissue of rat in DMBG WKY group; C: renal tissue of rat from NC SHR group; D: kidney tissue of rat from DMBG SHR group

\section{DISCUSSION}

Hypertension has attracted the attention of medical scholars in China and abroad as a result of its accentuated incidence and related coronary and kidney complications. Patients with hypertensive nephropathy may present symptoms such as proteinuria, increased nocturia and hematuria, and in severe cases, uremia may develop, bringing heavy burden to families. In patients with long-term hypertension, the osmotic pressure in the glomeruli is very high, and the glomerular function is impaired, leading to proteinuria [8]. Therefore, proteinuria is the main feature of renal injury in patients with hypertension. Clinicians reduce the degree of renal injury in patients with hypertension by reducing proteinuria.

Metformin is widely used in treating type 2 diabetes because of its low side effects. In recent years, it has been found that metformin reduces insulin resistance and inflammatory response; improves vascular endothelial function, and mitigates atherosclerosis [9]. Studies have revealed that metformin inhibits the VEGF pathway of glomerular epithelial cells, thereby minimizing the incidence of diabetic nephropathy [10]. In this study, there were no statistically significant differences in blood glucose and body weight in SHR and WKY rats. Histology showed no morphological abnormalities in rat kidneys in NC WKY group and DMBG WKY group. Renal tissue inflammatory cell infiltration was lower in DMBG SHR rats than in group NC SHR, suggesting that metformin administration to nondiabetic rats had no effect on blood sugar, but improved inflammatory response in rats.

Creatinine (Cre) is a product of muscle metabolism which is filtered out of the body through glomerular filtration [11]. Under normal circumstances, the daily production of Cre remains almost constant, and the concentration of Cre is relatively stable. Thus, Cre is clinically used as an indicator of glomerular function [12]. In this study, the urine protein and Cre levels of metformin-treated rats were significantly lower than those of untreated rats, suggesting that metformin enhanced glomerular filtration and reduced the level of proteinuria in hypertensive rats to a certain extent. This indicates that metformin exerts renoprotective effect, which is similar to the experimental results of Yeqiong [13].

Vascular endothelial growth factor (VEGF) is a highly specific growth factor in vascular endothelial cells. It increases vascular permeability, promotes formation of new capillaries, improves the activity of plasmaactivating factor, and enhances the migration and proliferation of vascular endothelial cells [14]. Recent studies have shown that VEGF-A enhances and maintains glomerular filtration function which, when impaired, results in proteinuria [15]. In this study, the immunohistochemical status after metformin treatment of SHR and WKY rats revealed that renal expression of VEGF was significantly increased, when compared with VEGF-A expression in untreated rats. In DMBG SHR rats, VEGF-A level was markedly higher than that in NC SHR group, and VEGF-A level of rats in DMBG WKY group was elevated, relative to NC WKY group. This suggests that metformin improves glomerular filtration and reduces proteinuria by upregulating VEGF levels.

\section{CONCLUSION}

Metformin reduces proteinuria in spontaneously hypertensive rats and exerts renoprotective 
effect through the upregulation of VEGF. These results provide a new direction for studying the mechanism involved in the protection of the kidney by metformin.

\section{DECLARATIONS}

\section{Conflict of interest}

No conflict of interest is associated with this work.

\section{Contribution of authors}

We declare that this work was done by the author(s) named in this article and all liabilities pertaining to claims relating to the content of this article will be borne by the authors. All authors read and approved the manuscript for publication. Yuanyuan Liu conceived and designed the study, Yuanyuan Liu, Chengjian Wang, Enyuan Zhang collected and analyzed the data. Yuanyuan Liu wrote the manuscript.

\section{Open Access}

This is an Open Access article that uses a funding model which does not charge readers or their institutions for access and distributed under the terms of the Creative Commons Attribution License (http://creativecommons.org/licenses/by/ 4.0) and the Budapest Open Access Initiative (http://www.budapestopenaccessinitiative.org/rea d), which permit unrestricted use, distribution, and reproduction in any medium, provided the original work is properly credited.

\section{REFERENCES}

1. Ghofrani $H A$, Galiè N, Grimminger F, Grünig E, Humbert $M$, Jing ZC, Keogh AM, Langleben D, Kilama MO, Fritsch $A$, et al. Riociguat for the Treatment of Pulmonary Arterial Hypertension. N Engl J Med 2013; 369(4): 330-340.

2. Niklas AA, Flotyńska A, Zdrojewski T, Pająk A, TopórMądry R, Nadrowski P, Polakowska M, Kwaśniewska M, Puch-Walczak A, Bielecki $W$, et al. Trends in hypertension prevalence, awareness, treatment and control among Polish adults 75 years and older during 2007-2014. Cardiol J 2018; 25(3): 333-344.

3. Leung AA, Nerenberg K, Daskalopoulou SS, McBrien K, Zarnke KB, Dasgupta K, Cloutier L, Gelfer M, LamarreCliche M, Milot A, et al. Hypertension Canada's 2016 Canadian Hypertension Education Program Guidelines for Blood Pressure Measurement, Diagnosis, Assessment of Risk, Prevention, and Treatment of Hypertension. Can J Cardiol 2016; 32(5): 569-588.
4. Segel MJ, Kogan A, Preissman S, Agmon-Levin N, Lubetsky A, Fefer $P$, Schaefers HJ, Raanani $E$. Pulmonary Endarterectomy Surgery for Chronic Thromboembolic Pulmonary Hypertension: A SmallVolume National Referral Center Experience. Isr Med Assoc J 2019; 21(8): 528-531.

5. Chen HM, Zhang XJ. effects of lipoic acid injection combined with metformin on urinary microalbumin and oxidative stress levels in patients with early type 2 diabetic nephropathy. J Guangxi Med Univ 2016; 33(5): 826-828.

6. Rowan JA, Rush EC, Plank LD, Lu J, Obolonkin V, Coat $S$, Hague WM. Metformin in gestational diabetes: the offspring follow-up (MiG TOFU): body composition and metabolic outcomes at 7-9 years of age. BMJ Open Diabetes Res Care 2018; 73(10): 565-567.

7. World Health Organization. Principles of laboratory animal care. WHO Chron 1985; 39: 51-56.

8. Marques FZ, Nelson E, Chu PY, Horlock D, Fiedler A, Ziemann M, Tan JK, Kuruppu S, Rajapakse NW, ElOsta $A$, et al. High-Fiber Diet and Acetate Supplementation Change the Gut Microbiota and Prevent the Development of Hypertension and Heart Failure in Hypertensive MiceClinical Perspective. Circulation 2017; 135(10): 964-977.

9. Dela Cuesta-Zuluaga J, Mueller NT, Corrales-Agudelo V, Velásquez-Mejía EP, Carmona JA, Abad JM, Escobar JS. Metformin Is Associated with Higher Relative Abundance of Mucin-Degrading Akkermansia muciniphila and Several Short-Chain Fatty AcidProducing Microbiota in the Gut. Diabetes Care 2017; 40(1): 54-62.

10. Frã As JP, Guja C, Hardy E, Ahmed A, Dong F, Öhman $P$, Jabbour SA. Exenatide once weekly plus dapagliflozin once daily versus exenatide or dapagliflozin alone in patients with type 2 diabetes inadequately controlled with metformin monotherapy (DURATION-8): a 28 week, multicentre, double-blind, phase 3, randomised control trial. Lancet Diabetes Endocrinol 2016; 4(12): 1004-1016.

11. Zhang R, Liu L, Zhou H, Chan EW, Li J, Fang $Y, L i Y$, Liao K, Chen S. Nationwide Surveillance of Clinical Carbapenem-resistant Enterobacteriaceae (CRE) Strains in China. EBioMedicine 2017; 19: 98-106.

12. Kim HS, Li Z, Boothroyd C, Cross GA. Strategies to construct null and conditional null Trypanosoma brucei mutants using Cre-recombinase and loxP. Mol Biochem Parasitol 2013; 191(1): 16-19.

13. $L i$ YQ. Effects of metformin on AGEs expression in kidney tissues of rats with type 2 diabetes mellitus. Chin Pharm Bull 2018; 34(5): 615-619.

14. Li YL, Zhao H, Ren XB. Relationship of VEGF/VEGFR with immune and cancer cells: staggering or forward. Cancer Biol Med 2016; 13(2): 206-214.

15. Kim DY, Lee SS, Bae YK. Colorectal cancer cells differentially impact migration and microRNA expression in endothelial cells. Oncol Lett 2019; 18(6): 6361-6370. 